\title{
Football intermediaries and self-regulation: the need for greater transparency through disciplinary law, sanctioning and qualifying criteria
}

\author{
Gregory loannidis ${ }^{1,2} \mathbb{D}$
}

Published online: 28 August 2019

(c) The Author(s) 2019

\begin{abstract}
This paper was first presented at the International Sports Law Conference in The Hague in October 2018. It summarises the author's work and wider research on the introduction of new proposals for the regulation of football intermediaries (a term which the author finds unworkable and unorthodox). The author's research critically analyses the current regulatory framework and identifies the elements that form the basis for the inadequacy and ineffectiveness of the regulations currently in force. With the use of case studies and examples drawn from the author's private practice, recommendations are produced for new regulations that would promote transparency, equality and consistency. The author concludes that this can only be achieved via a blending of self-regulation and external regulation at an international setting.
\end{abstract}

Keywords Sports law $\cdot$ Football law $\cdot$ Agents $\cdot$ Regulation $\cdot$ Arbitration

\section{Introduction}

It is more often than not when a high-profile football dispute (or allegation therein) sees the public light. It is arguable that the enormous commodification of the game, along with the considerable and undisputed increase in the use of social media (and their impact on public opinion), has created an inevitable framework of open public discussion, where ideas, opinions and criticism are exchanged. Such open discussion regularly highlights the role of football agents and, inevitably, focuses on the ability, or otherwise, of governing

Dr Gregory Ioannidis is a sports lawyer and an anti-doping litigation expert. He is a former The FA registered lawyer (RLI 336) and has acted for and represented many players and clubs around Europe, Africa and Asia. He is currently the Course Leader of the Master's Programme LLM International Sports Law in Practice at Sheffield Hallam University and a member of the Academic Panel of Kings Chambers in Manchester.

Gregory Ioannidis

g.ioannidis@shu.ac.uk

1 Course Leader - LLM International Sports Law in Practice, Department of Law and Criminology, Sheffield Hallam University, Sheffield, UK

2 Kings Chambers, Manchester, UK bodies to regulate properly and appropriately, the business of football agency.

\subsection{The background}

There is one aspect that the author needs to clarify before he proceeds with the analysis of the present work. Throughout the present analysis, the author will respectfully use the term 'agent,' as opposed to the term 'intermediary.' In the author's opinion, the term 'intermediary' does not fully describe the actual work done by many professionals in this business. It does not also describe and afford the recognition that some of them must receive for their enormous contribution to the game as a whole and to their individual clients. As the author states above, the term is unworkable and unorthodox and FIFA must respectfully consider the immediate withdrawal of such term.

In addition, the author possesses over 15 years of experience in representing players at the highest level and he has been involved in a number of difficult and complicated transactions. Such transactions allowed the author to experience and appreciate the different dynamics operating in the market and the numerous ways by which football agents deal with certain situations. It has also allowed the author to appreciate that, sometimes, such dynamics are disguised and well hidden. It is because of the author's involvement, 
in this market, that he can appreciate the limitations of selfregulation and he is hoping that the present work will inform and strengthen this important area of football law, within the wider discipline of sports law.

Further, it is also important to underline the actual problems/issues with the regulation of football agents and justify the premise for the present research and work. In doing so, the author hopes that the readers shall be able to appreciate the significance of this area of regulation, not only for the discipline of sports law, but for society too.

The role of a football agent in modern society is multifaceted, and it cannot be limited only to negotiations leading to the transfer of a player between two clubs. If done appropriately and in a professional manner, it requires the agent to perform a series of different functions such as scouting, counselling, assistance with financial/tax services, evaluation and execution of image rights and the securing of sponsorship/marketing opportunities. Such functions are largely unknown, at least to the public, but they play an important role towards maximisation of the player's commercial and employment opportunities.

There are, however, other situations that may lead football agents to proceed with unethical and illegal practices and such situations remain secret, unless there is media exposure. ${ }^{1}$ It is these situations that, when exposed, create an environment of distrust among the stakeholders and particularly among the public. Our research indicates that a large segment of practicing football agents wishes such illegal and unethical practices to be eradicated, whereas the public feel that unscrupulous (unlicensed and unregulated) agents damage the image of sport. The author represented several football agents before disciplinary hearings, either before The FA's Rule K Arbitration, or at other jurisdictions, where allegations of tapping up, contractual breaches and/or incitement to commit such breaches were presented. It is remarkable that in almost half of the cases the author had the opportunity to deal with, the allegations concerned football agents who were unlicensed (or unauthorised to deal with specific players) and in one-third of them, the agents concerned did not really understand the professional responsibility that applied to them. In some of those cases, it was clear that the advice offered by those agents to players was damaging, as basic principles of contract law and/or employment law were ignored, with the result to cause the players to be bound by an employment contract of a considerable duration, which contained several provisions that were not beneficial to the player. In the same number of cases, it was also evident that

\footnotetext{
${ }^{1}$ See, for example, the inquiry by Smith \& Lord Stevens https:// www.theguardian.com/football/2007/jun/15/newsstory.boltonwand erers and the BBC Panorama investigation http://news.bbc.co.uk/2/hi/ programmes/panorama/5363702.stm.
}

the concerned agents did not really understand or appreciate professional ethics, nor did they have an intention of applying such ethics. In some other cases, several players were approached by third-party agents and were persuaded to breach their existing player-agent mandate of representation. The damage and the loss to the complainant agent (or player) in such situations were irreversible and contributed to the argument that unregulated and unscrupulous agents have no place in this discipline. In one of our interviews conducted with one of the current Premier League managers, the comment was: 'I do not like dealing with any of them (agents). They are parasites, vermin of the worse kind and I have no time for them. Go no further, this is the Wild West. ${ }^{, 2}$ Another Premier League manager declared: 'I have dealt with over 50 agents in the last three years and I am still waiting to meet a decent one. Many of them, if not all of them, have their own interests at heart, not their clients.' They seek a quick profit and in order for them to get it, they will step on bodies. They are all mafiosos.' In addition (and further to the evidence in Footnote 1), there are several other situations that give rise to allegations of tapping up, bungs, tax evasion and many more activities that centre around the practices of football agents. All these situations have the potential of damaging the image of sport and creating a reputational risk for the different stakeholders in the sport.

It is submitted that evidence to this effect could only help one to appreciate the level of dissatisfaction expressed by mane stakeholders in this area. Whether this is a legal problem or an ethical one (or both), it can be submitted that the damage the sport suffers must be measured against the significance of sport for society. Such significance cannot be underestimated, nor can it be dismissed at face value. This significance is understood by self-regulation, but it is more often than not, that its governance fails its participants and other stakeholders. This is true in the area of regulation of football agents, which, at the moment, appears to be at its lowest since its inception. The analysis in the present work clearly identifies 'deregulation' as one of the two major factors of the present problematic situation, whereas the second factor relates to the lack of appropriate sanctions against those who violate the current regulatory framework (where applicable).

Following from the arguments above, one may question the necessity for the discipline of sports law to look deeper into this area of regulation. In other words, why does the area of football agents deserve such special enquiry? The answer to such question may allow the reader to elicit the significant problems in the regulation of football agents. Firstly, the enormous amounts of money that relate to the

\footnotetext{
2 Interviews with current premier league managers were conducted in May-July 2018.
} 
transfers of professional football agents create an attractive environment of employment where any individual (without skills and/or relevant qualifications) can enter and make a profit. The evidence discussed in this work clearly indicates that unskilled and untrained agents may cause severe legal problems for their clients and/or other agents, particularly on issues of contract law and/or employment law. Secondly, the relative ease by which individuals can enter (and perform) the profession of a football agent and the current deregulation of such profession, create, as already stated, ethical and legal problems. An open profession, without regulation and with an attractive and quick remuneration, attracts all sorts. Thirdly, the lack of appropriate sanctions, where regulatory violations occur, contributes significantly to the perpetual existence of the issue and damages the image of sport. The last point has enormous significance for the justification of the argument that the legitimacy of self-regulation and governance is severely dented.

\section{Methodology}

The present work combined qualitative and quantitative methods of research, over a period of 28 months. Qualitative methodology allowed us to understand human behaviour from the respondents' perspective, and data were collected through interviews and other methods of observation. This, in essence, provided us with an opportunity to understand how the respondents perceive their environment and, consequently, how they see social realities that connect with their own environment. We interviewed ten football managers from each of the six different countries in which the research took place, ${ }^{3}$ ten professional players and ten agents. The interviews were unstructured, with open questions, and this created an interpretive environment.

On the other hand, our quantitative research focused on a closed-ended questions survey, conducted in the same six countries. The respondents were registered football agents, and the responses were collected by our research team on an anonymous basis. The data collected and subsequently analysed can be described as accurate, concise and clear. The six countries were chosen because of their numerical supremacy (save for Greece where the data were smaller) and the concentration of football finances data/principles. For example, the "big five" ${ }^{4}$ European leagues generated $€ 14.7 \mathrm{bn}(£ 12.6 \mathrm{bn})$ in $2016 / 17$, as opposed to $€ 8.4 \mathrm{bn}$ in 2010/11 (Deloitte 2016 and 2011). In addition, the total wage costs of the 'big five' leagues generated $€ 8.5 \mathrm{bn}$ in

\footnotetext{
${ }^{3}$ UK, Germany, France, Italy, Spain and Greece.

${ }^{4}$ UK, Germany, France, Spain, Italy.
}

2016-2017, an increase by 4\% (Deloitte 2018). ${ }^{5}$ Finally, player-transfer expenditure by Premier League clubs, for example, produced a record of $£ 1.6 \mathrm{bn}$ in the 2016/-2017 season. This expenditure created a larger share for the agents too, producing $£ 174 \mathrm{~m}$ on fees paid to them (Deloitte 2018).

The interviews were conducted personally by the author, by utilising his contacts and colleagues in the players' transfer market, whereas the survey was sent (via email) to those agents who are registered in the aforementioned leagues. At this juncture, we would like to extend our appreciation to the football associations who kindly provided us with the necessary and relevant details. Such assistance allowed us to commence our project and enabled us to collect and evaluate the necessary data. In terms of the quantitative data collected from the survey, we succeeded in contacting 3089 registered agents in the relevant six leagues. This represents a $44 \%$ of the entire agents' population around the world.

The survey focused on two different sections, where in Section I the background of the agents was analysed, such as education, experience and knowledge of the market, whereas Section II concentrated on fifteen major questions, leading us to answers that were important for the identification of those roots that create inconsistency and arbitrariness in the effective regulation of football agents. In summary, we produce five questions here (from Section II) that are relevant to the aims of the research:

1. Do you fully understand the FIFA Regulations on Intermediaries?

2. Do you have knowledge of Contract Law and/or Employment Law?

3. Do you hold a valid mandate of representation with your clients?

4. Do you follow the recommended $3 \%$ benchmark fee suggested by FIFA on relevant commission?

5. If the answer to Question 4 is 'No,' what is the reason for not following the $3 \%$ benchmark $^{6}$

We were very pleased with the number of responses we received, as we sent out 3089 invitations and we received 2245 responses. This represents a very solid $72.6 \%$ of answers, giving, therefore, our research statistical probity, which enabled us to confirm and accurately evaluate our findings. This was in line with our initial aim to create an experiential knowledge process, by incorporating disciplinary and discursive practices, in order for us to understand the relevant field of endeavour (Cetina 1999; Latour and

\footnotetext{
5 Annual Review of Football Finance 2018, Deloitte.

${ }^{6}$ Four choices for the answer were provided to the respondents, in relation to Question 5: a. Too low, b. Everybody else does the same, c. It is not mandatory, d. I don't know.
} 
Woolgar 1986). This process was important for our research as this is a highly unregulated area, within the wider discipline of sports law, and it was important for the author to confirm (or counter) the existing knowledge in conjunction with the actual reality. When reality comes into being, knowledge becomes accurate and comprehensive and the data collected confirmed three different issues:

a. There is an unregulated environment which allows unethical and unscrupulous activities, with the result to create an undisputed reputational risk against football agents, players and other stakeholders in the sport.

b. The uncontrollable commodification of the game of football (in conjunction with the lack of adequate regulation) and the unmonitored financial rewards diminish the abilities of self-regulation and damage the image of sport.

c. The lack of appropriate action (sanction) against perpetrators weakens any arguments for the continuation of the autonomy of sport and its governance by selfregulation.

These issues are all analysed in great detail below, but it is first of all necessary to outline the previous and current regulations, so the reader can appreciate the problems that make the need for the present work relevant, necessary and imperative.

\section{The previous regulations}

Although the representation of football players by agents may be traced back to the early years of the introduction of football as a regulated sport, it was not until 1994 when FIFA $^{7}$ decided to create the Players' Agents Regulations, to regulate the activities of such individuals. In their first format, such regulations created strict licensing criteria and placed a burden on clubs and players to engage only agents that possessed a valid licence. Pre-requisites for the issuance of the licence included a 'clean' criminal record and a bank guarantee of $200 \mathrm{k}$ Swiss Francs (in the form of a deposit).

In 1999, the European Commission was called upon to investigate complaints (brought forward by football agents) based on allegations of restrictions to the market, discrimination on citizenship and lack of remedies on decisions re-entered by disciplinary bodies. ${ }^{8}$ The EC issued a statement of objections, ${ }^{9}$ following an investigation into the

\footnotetext{
7 The world's governing body for the game of football.

${ }^{8}$ Complaints were brought forward by Multiplayers International Denmark and the French football agent Laurent Piau.

9 The commission stated that the prohibition against unlicensed agents and the exclusion of legal persons from representing players, may fall foul of competition law.
}

allegations. FIFA decided to respond to such objections and, with the introduction of the 2001 Players' Agent Regulations, removed some of the restrictions. It retained, however, the regulations that concerned the ability of natural persons only to hold a licence, and it also created an amendment which authorised national associations to issue licences to agents registered with them. At the same time, FIFA reenforced (into its regulatory framework) the requirement of the 'impeccable reputation' to be applied to those who wished to obtain a licence and it further introduced an examination which tested the applicant's knowledge on the law that related to football. Although the French agent Piau continued to challenge the validity/legality of these regulations, the General Court ${ }^{10}$ confirmed that FIFA Regulations do not violate EU competition law. ${ }^{11}$ In doing so, the Court took the opportunity to state that FIFA may impose qualitative restrictions on agents, an argument which meets with the author's agreement and, upon which, much of the present work is based. In addition, and on a point, which is of immense importance to the present work, the Court refused to assess the legal basis of FIFA's ability to regulate agents, but it took the opportunity to state that FIFA displays no abuse of a dominant position (on this point), particularly where there is an absence of state control, in the form of external regulation. ${ }^{12}$

The above may help the reader appreciate that there have been many attempts by FIFA, over the years, to regulate the activity of football agents. The decision to regulate such activity may also form a determinative, persuasive and comprehensive indicator towards the argument that such is the importance of this activity, as well as its size and impact on the relevant market that some kind of regulation must be in place. Three major revisions have taken place in the last few years (2006, 2008 and 2015), testament to the complexity and the speed by which such market moves. FIFA has not been laconic in its production of the relevant regulations, but the last revision (2015), which gives emphasis to the present applicable regulations, has identified a considerable degree of deregulation and forced FIFA to assume the role of Pontius Pilate.

Although FIFA must accept its share of responsibility and acknowledge that there is a major problem with the regulation of football agents, some responsibility must also

\footnotetext{
$\overline{10}$ Former European Court of First Instance.

11 Case T-193/02 Laurent Piau v Commission of the European Communities [2005] ECR II-209. On appeal, the European Court of Justice also upheld the General Court's decision, see: Case C-171/05 P, Laurent Piau v Commission of the European Communities, Order of the Court (Third Chamber) of 23 February 2006, ECR 2006 I-37.

12 Although this position may still be valid, it is worth noting that several Member States in the EU now have sport specific legislation to cover and regulate the activities of football agents.
} 
be directed towards the different and numerous stakeholders that operate in the same market, be it sporting officials, clubs, dispute resolution fora (at national level) and so on. FIFA recognises that it is potentially difficult and inevitably certain for it to conclude that it cannot regulate agents at an international stage, but FIFA must also accept that its role (the secret is in its title), leaves no room for any other option. In conjunction with this, FIFA must also accept that without the assistance of external regulation (state authorities and/ or law enforcement agencies), it cannot possibly expect an elimination of the problem it is currently facing.

Having said that, one must query the root of the problem, regarding the regulation of football agents and attempt to elicit, with constructive criticism, the attempts made by FIFA, over the years, to tackle the problem with appropriate means and efforts. Our research indicates that there have been many factors for the dramatic increase in the number of practising agents. The case of Bosman ${ }^{13}$ inevitably formed the basis for such dramatic increase, as the free movement of persons has created commercial and employment opportunities that maximised the potential of synergies between agents and players. ${ }^{14}$ On this point, it is worth noting the significance of football agents in scouting and recruitment of young talented players, which, in essence, replaced the status quo of a club as a primary source of scouting (Magee 2002; Poli 2010). From the author's experience and practice in this area, there are situations where the power shifts from a club to an agent, in that the agent has the ability to control (subject to resources and networks) not only the availability of talented players worldwide, but also to access financial information on salaries, bonuses and so on, with the result of being in a position of power to negotiate more lucrative contracts for his/her clients. Our research, however, also indicates that it is not Bosman alone that allowed for such dramatic increase in football agents. Although Bosman was certainly the catalyst towards expansion of the market, nevertheless, our research shows that there are two other fundamental aspects responsible for such increase: firstly, the relative ease by which agents can now enter the market (and consequently approach and advise clients) and the quick

\footnotetext{
13 Union Royale Belge des Sociétés de Football Association ASBL v Jean-Marc Bosman C-415/93, European Court of Justice.

14 Although there are several competent and able football agents, there are also, regrettably, several unskilled and untrained agents, who enter the market with the sole intention of making a quick profit. The European Commission may feel that entry restrictions to individuals have the potential of violating EU competition law; however, the European Commission has also acknowledged in the Piau case that it is important for a regulator to have some control over those who operate in this market, particularly when there is absence of national legislation and/or regulation. This is an important point which offers probity to our proposal for a closer cooperation between external regulation and self-regulation, regarding the activities of football agents.
}

and, to a certain extent, unaccounted remuneration they can receive. Such aspects make the market extremely attractive and confirm the fact that the commodification of the game may be the underline reason of the problem.

The first argument clearly illustrates the 'open door' policy that currently exists. FIFA does not impose licensing restrictions on football agents (as the system of registration has now passed on to national federations), although some jurisdictions, such as Belgium, still require agents to possess a valid licence. This considerable deregulation by FIFA is an element of concern and it explains the statistical and empirical evidence currently in force, which shows an increase in the number of football agents, in several different national jurisdictions. In England, for example, the freedom to become a football agent is unlimited (and considerably unrestricted), as long as the applicant possesses an 'impeccable reputation,' no criminal record and no conflict of interest. ${ }^{15}$ In conjunction with this argument, the reader would be interested in the premise that there are also no educational qualifications restrictions, although it is fair to say that our research indicates that $68 \%$ of those who responded to our survey hold a university degree (only $12 \%$ hold a law degree and $27 \%$ have knowledge of law-related subjects), $23 \%$ hold a Master's degree, whereas a 5\% are at a Doctorate level.

The second argument, which illustrates largely the attractiveness of the profession of a football agent, forms the determinative factor for the escalation in the number of football agents. There is an escalation on agents' fees (in their overall remuneration), and clubs, in particular, are prepared to splash on agents' fees to ensure they sign their player of preference. Although the quality of the player would determine the negotiating power of an agent, clubs, nevertheless, are prepared to remunerate the agent by meeting, sometimes, his/her exorbitant requests, in order for them to secure the services of the player.

The statistical analysis of four seasons (2014-2018) in the English Premier League, for example, shows a dramatic increase in the remuneration of football agents, among the so-called big-six clubs in the league. The agents' fees almost doubled, for such clubs, from 2014 to 2018. In addition, the trend does not maintain national boundaries, but rather it has the potential of worldwide expansion. For example, since 2013, a total of 69,505 international transfers occurred worldwide, whereas $19.7 \%$ of those transfers $(13,672)$ involved at least one agent. In $47.8 \%$ of such transfers, where there is a transfer fee, there is at least one agent acting either for one of the clubs or for the player. From January 2013 to

\footnotetext{
152015 FIFA Regulations on football intermediaries. In addition, the applicant must pay a registration fee of $£ 600$. The same applies to registered lawyers.
} 
Table 1 FIFA/TMS

'Intermediaries in International
Transfers' 2017 ed.

\begin{tabular}{lr}
\hline England & 489.9 \\
Italy & 343.8 \\
Portugal & 161.1 \\
Germany & 145.6 \\
Spain & 121.7 \\
France & 61.4 \\
Belgium & 31.4 \\
Russia & 30.7 \\
Wales & 29.3 \\
Croatia & 19.9 \\
\hline
\end{tabular}

date, $\$ 1.59$ billion was paid as commissions to club agents. ${ }^{16}$ Our readers may also wish to compare this with the $£ 66$ million figure spent on agents in the 2007-2008 season. ${ }^{17}$

\subsection{The 2008 regulations}

The 2008 revision of the regulations on football agents produced considerable developments and paved the ground for the deregulation that FIFA was looking for. Although the obligation of agents to pass an examination, remained in place, FIFA introduced the principle of 'impeccable reputation' (only natural persons) ${ }^{18}$ that agents had to show they possessed and, upon meeting with such requirement, national federations would issue licences to agents who met with the criteria. This was the starting point for FIFA's intention to deregulate the business of football agents and made it clear that it was the national federations' responsibility to license football agents (although several agents continued, euphemistically, to use the term 'FIFA agent' - and some of them still do, the truth of the matter remains that there is no such thing as a 'FIFA agent'). All other basic provisions remained, by and large, the same, with a notable focus on FIFA's attempt to maintain specific standards and ensuring that players are not exploited and that financial records and/or payments are kept and monitored. For example, the 2008 Regulations created a requirement for a legal guardian to sign the representation contract of a minor, ${ }^{19}$ whereas the agent was required to file a copy of the representation contract with the relevant national federation, ${ }^{20}$ including

\footnotetext{
${ }^{16}$ See Table 1-FIFA TMS "Intermediaries in International Transfers" $2017 \mathrm{Ed}$.

17 Kelso, P. 2009. 'Premier League Wages Soar as Agents Paid £66 million.' Daily Telegraph, June 4.

18 Article 6.1 of the 2008 Regulations.

19 Article 19.2 of the 2008 FIFA Regulations.

20 Article 19.6 of the 2008 FIFA Regulations.
}

all the details of the contractual relationship (names, dates, signatures, duration, representation, jurisdiction, etc.). ${ }^{21}$

Despite the presence of all these basic but important contractual considerations, as well as the licensing process and the examination in place (at least for some federations worldwide), the principle of 'impeccable reputation' continued to create an enormous and unjustified subjectivity around different federations. Add insult to injury, such principle, was applied in very unequal and arbitrary terms around different jurisdictions and confirmed that a 'federal system' of deregulation and decentralisation was not going to be successful. The undersigned, witnessed far too many situations (either as legal counsel or agent) where the principle of 'impeccable reputation,' if applied purposefully and appropriately, would have allowed for the striking off of many agents in specific jurisdictions. In addition to this argument, one must not dismiss at face value the fact that one of the reasons the regulatory framework remained ineffective is not because the regulations lacked strength, but rather because their execution has been arbitrary, capricious and, on certain occasions, nonexistent. On at least two occasions, the author was the recipient of the actions of two agents who, on both occasions, attempted to incite a breach of a representation contract, with the view to luring away the author's clients. When the author complained to the relevant national federation (and to FIFA), the culprits were simply cautioned. ${ }^{22}$ Similarly, the author represented (before relevant disciplinary Tribunals) several football agents who complained of incitement to breach and breach of a valid mandate of representation by unauthorised third-party agents. On such occasions it was evident that such third-party unauthorised agents attempted to approach players, who were under a valid mandate of representation with other agents and persuade them to breach their existing mandate. Regrettably, this is a situation that occurs regularly, and it does so, because of the lack of appropriate regulation and application of sanctions against the perpetrators. It is respectfully submitted that this is, perhaps, the biggest problem in the regulation of football agents and one which violates, considerably, the contractual stability that both FIFA and UEFA wish to instil in the professional relationships between the different stakeholders.

It is respectfully submitted, therefore, that it is this lack of appropriate execution of the relevant regulations and the lack of sanctions against perpetrators that made the entry to the profession even more attractive and contributed to the continuation of the present situation. ${ }^{23}$

\footnotetext{
21 Article 19.5 of the 2008 FIFA Regulations.

22 Both agents still practice with one of them being constantly in the public eye for a number of activities connected with his profession.

23 Although there is a contention that football agency does not give rise to a profession, the author respectfully disagrees with such contention.
} 


\subsection{The 2015 regulations}

The introduction of the 2015 Regulations on football agents created a comprehensive form of deregulation. This is evident from the clear acknowledgement produced by FIFA, outlining its intention to do so and explaining the reasons. ${ }^{24}$ In essence, FIFA acknowledged that the 2008 set of regulations on football agents did not work and explained that this failure relates to the fact that only $25-30 \%$ of licensed agents are responsible for players' transfers. The author respectfully disagrees with such contention and would like to re-enforce the point that had FIFA maintained a tight monitoring process on agents' activities and enforced strictly and indiscriminately its regulatory framework against unscrupulous agents, there would be no need for any new set of regulations, let alone for a comprehensive form of deregulation.

With this in mind, let us summarise the 2015 FIFA Regulations on football agents:

- The preamble to the regulations introduces the first change that relates to the term applicable to those involved in football transfers. It states: 'A natural or legal person who, for a fee or free of charge, represents players and/or clubs in negotiations with a view to concluding an employment contract or represents clubs in negotiations with a view to concluding a transfer agreement.' Please note that legal persons can now enter into transactions and as the author explains below, this potentially opens the way for further malpractice, particularly where the legal person involved in the transaction is a company registered overseas.

- The most notable change relates to the abolition of the licensing system. ${ }^{25}$ National football federations are no longer required to have a licensing system and the only requirement relates to a registration system, where national federations are only required to put in place a registration system through which 'intermediaries' are registered for every individual transaction they are involved in, whether it is with a club or with a player [emphasis added].

- Another notable recommendation (as opposed to a mandatory provision) relates to the remuneration of agents, which states that agents should not receive more than $3 \%$ of the player's basic gross income for the duration of the contract (3\% of the transfer fee when the agent has been

${ }^{24}$ See Marco Villiger, FIFA's Legal Director in the EU Conference on Sports Agents, Brussels, 9-10 November 2011, http://ec.europ a.eu/assets/eac/sport/library/studies/final-report-eu-conference-sport s-agents.pdf.

25 Article 11.2 of FIFA's Regulations Working with Intermediaries. engaged on behalf of the club). ${ }^{26}$ In practice, it is hardly ever the case that an agent would claim a $3 \%$ fee in relation to a transaction. (From the author's experience, fees may range from $5 \%$ to $18 \%$.) In addition, it is the author's opinion that if such a recommendation were to receive a mandatory nature, it would highly likely be challenged before courts and it is almost certain that it would fall foul of Articles 101 and 102 on distortion of competition and abuse of a dominant market position. ${ }^{27}$

- Another amendment which causes immense criticism relates to the requirement of those agents of 'impeccable reputation' to ensure that they have no relationships that could lead to a 'conflict of interest.' Our respectful submission on this point is that this situation gives rise to a 'much ado about nothing' argument. In addition, wellpublicised examples indicate the prevalence of situations that FIFA is trying to stop. ${ }^{28}$

Considering the above (at this juncture), our research data, below, indicate that after over three years into the application of this new set of regulations, the problems have become even greater. To this effect, a comprehensive argument can be made that the lack of barriers to individuals who are unskilled, untrained and lack knowledge of the relevant regulations, are all elements that have a tendency of making the problem more serious. Such elements could potentially damage not only the image of sport, but they may create irreparable situations of negligence involving football players and/or clubs. In addition to this argument, the introduction, by FIFA, of relevant regulations that allow commercial entities to enter into agency transactions, now creates a wider and increasing field of tax avoidance schemes and poses a threat to the financial stability of several stakeholders in the sport. In this light, it is the author's respectful submission that there is no reasonable or compelling justification for this deregulation, as in essence, such deregulation damages the image of sport as a whole.

Further, another element of the 2015 Regulations, which creates a procedural limitation, relates to the ability (or lack of) of litigants to use available appellate proceedings. One of the most important aspects of the procedural and substantive advantages the discipline of sports law may entertain in this area of practice, centres on the choice of arbitration litigants may have and the choice of the appropriate dispute resolution forum. It is evident from a purposeful interpretation of the current regulations that FIFA has a preference for national federations to deal with national disputes (many

\footnotetext{
26 Article 7 of FIFA's Regulations Working with Intermediaries.

27 Treaty on the Functioning of the European Union 2012/C 326/01.

${ }^{28}$ See The Guardian, 10 May 2017, https://www.theguardian.com/ football/2017/may/10/mino-raiola-manchester-united-paul-pogba.
} 
Fig. 1 Academic \& Training Process

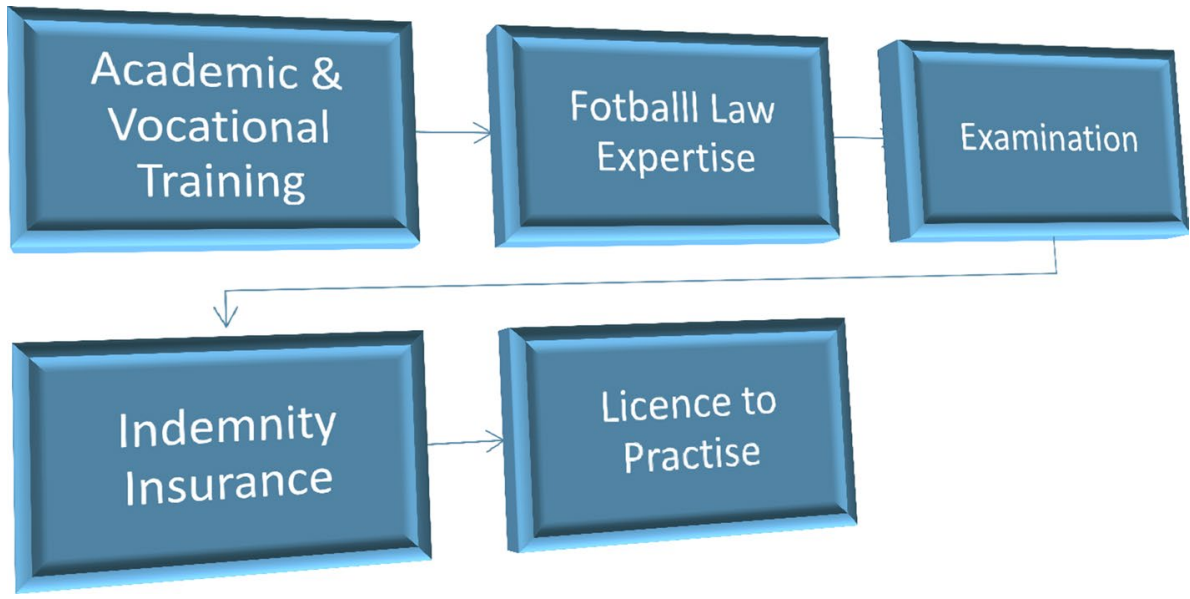

national federations do not allow for appeals to CAS). ${ }^{29}$ FIFA has, however, also left a window open for itself, which allows it to intervene in national disputes when there is a need for further sanctions. There is, however, ample evidence to suggest that the plethora of disputes, the lack of resources and personnel and other political reasons in the decision making of national federations, may not allow national federations to apply and execute such regulations in an effective and efficient manner. In such situation, litigants may find themselves short of a remedial avenue, as FIFA has created a jurisdictional limitation where parties have no possible avenues for appeals to the Court of Arbitration for Sport (CAS). This lacuna clearly illustrates such jurisdictional issues litigants may face, particularly where they are unhappy with a decision at national level. Unless there is a specific agreement at national level, which allows for an appeal to CAS (and usually there is not), and/or FIFA has decided to intervene and reached a decision (in which case litigants may appeal it to CAS), CAS applications may be restricted because of the described jurisdictional limitations.

\section{Our proposals: the way forward}

It is not the author's intention to appear pedantic, nor is there an attempt, with the present work, to underestimate the professionals in this discipline. It is important, however, to recognise (and our research suggests so) that there is a significant and, rather, increasing number of unskilled, untrained and unqualified agents, dealing with complicated and highly sensitive matters that determine the livelihood of professional players. Like in any other highly skilled profession, there is a need for an academic and vocational training

\footnotetext{
${ }^{29}$ In the UK, the FA has created the Rule K Arbitration, which offers parties an appropriate dispute resolution forum.
}

stage, where professional responsibility is clearly explained to and applied by those who wish to enter the profession.

In the premises, it is submitted that the relationship between a football player and an agent is based on confidence and trust and the advice given to the player, particularly where there is a long-term contract with serious consequences for the party signing it, may give rise to negligence and cause loss and damage to the player. In such instance, one would be hard pressed to accept the damage and/or sweep it under the carpet. More interestingly, the question may arise as to who is going to pick up the bill and how, if the agent concerned has no insurance and/or has no income to meet a claim against him/her.

It follows, therefore, that an appropriate system of regulation is needed, to ensure that the rights of all parties to commercial transactions involving the transfer of players are secured, and that the system in place, guarantees that the individuals involved are properly qualified to advise on such commercial transactions.

In summary, and for the reasons explained below, we propose the introduction of Qualification Criteria and we recommend that only when such Qualification Criteria have been met, a licence to practise should be issued:

\subsection{Qualification criteria: process}

The diagram ${ }^{30}$ illustrates the process upon which we recommend that any new regulations must be created and executed. This process also illustrates our recommendations for the re-introduction of a licensing system, but with pre-existing strict qualification criteria. We also recommend that such process is monitored and supervised by independent professional bodies, operating at a national level, with the cooperation of national federations and independent scientific

\footnotetext{
$\overline{30}$ See Fig. 1.
} 
Fig. 2 Research Data 1

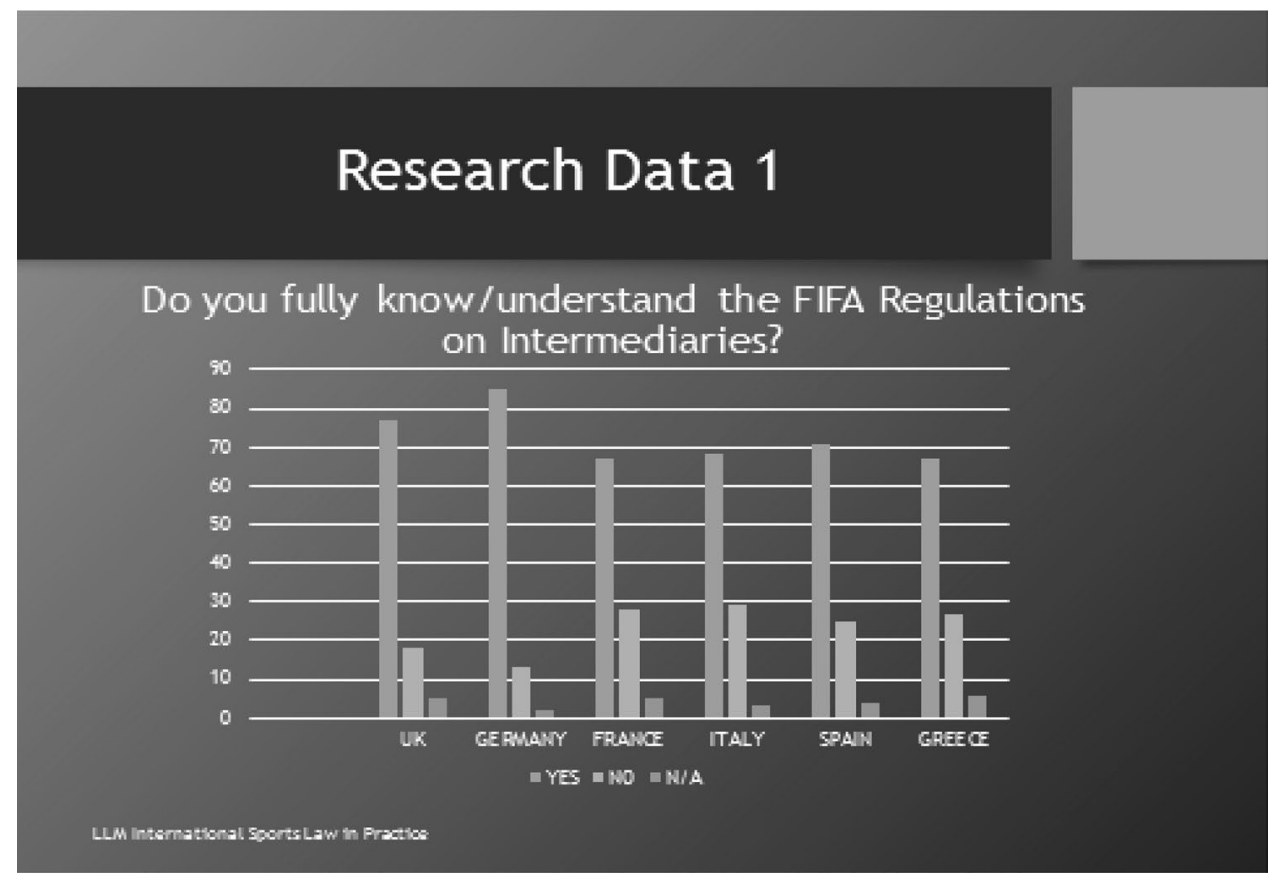

councils. The membership of such professional bodies must be comprised of sporting officials and scientific/academic personnel unconnected to the administration and/or governance of football at national or international level. Such membership would ensure transparency at national level, integrity, consistency and equality in the licensing system and it would, above all, ensure that only qualified individuals are permitted to practise the profession of football agent. As we explain below, there is a compelling justification for the re-introduction of the licensing system and our recommendation is that FIFA must also play an important role of contribution towards a monitoring system. In the premises, it is submitted that FIFA has a wealthy existence in terms of finances and part of its funding to its members must include financial assistance towards the creation and running of such professional bodies. This would also ensure that FIFA's workload remains light, ${ }^{31}$ where national dispute resolution mechanisms are concerned.

\subsection{The process: academic and vocational training, examination and licensing}

The first stage in the licensing process should include the necessary academic and vocational training for professionals who wish to practise as football agents. This is an important and necessary stage of qualification, which ensures that the

\footnotetext{
${ }^{31}$ Quite possibly this is one of the major concerns for FIFA and the reasoning for a decision to de-regulate the profession of football agents.
}

individuals involved have the depth and breadth of knowledge, as well as the skills and training to advise clients in a confident, comprehensive, competent and professional manner. As our Research Data 1 and 2 below indicate, many current acting football agents lack the appropriate and necessary knowledge of the current applicable regulations. This is an area of concern as we explain below.

It follows, therefore, that the academic training of football agents is a necessary pre-condition for a successful licensing process. Such academic training must include a comprehensive introduction of compulsory modules in football law, with emphasis on contract law, employment law, law of tort (negligence), professional ethics and general principles of law. In addition, academic training must be followed by the necessary vocational training, where candidates are introduced into case studies, with real-life clients and disputes arising out of the expanding discipline of football law (and the game of football). There are a number of Institutions around the world offering such clinical and applied courses, with emphasis on the relationship between players and agents, although, in the author's opinion, FIFA must either create specific courses on such training, or promote and accredit existing ones that satisfy quality criteria.

The successful completion of such academic and vocational training will lead candidates towards an expertise in football law and upon successful examination of the aforementioned subjects, indemnity insurance must be obtained. Once such insurance has been obtained by the successful candidates, the relevant professional body should issue the certificate of qualification, register the successful candidate 
Fig. 3 Research Data 2

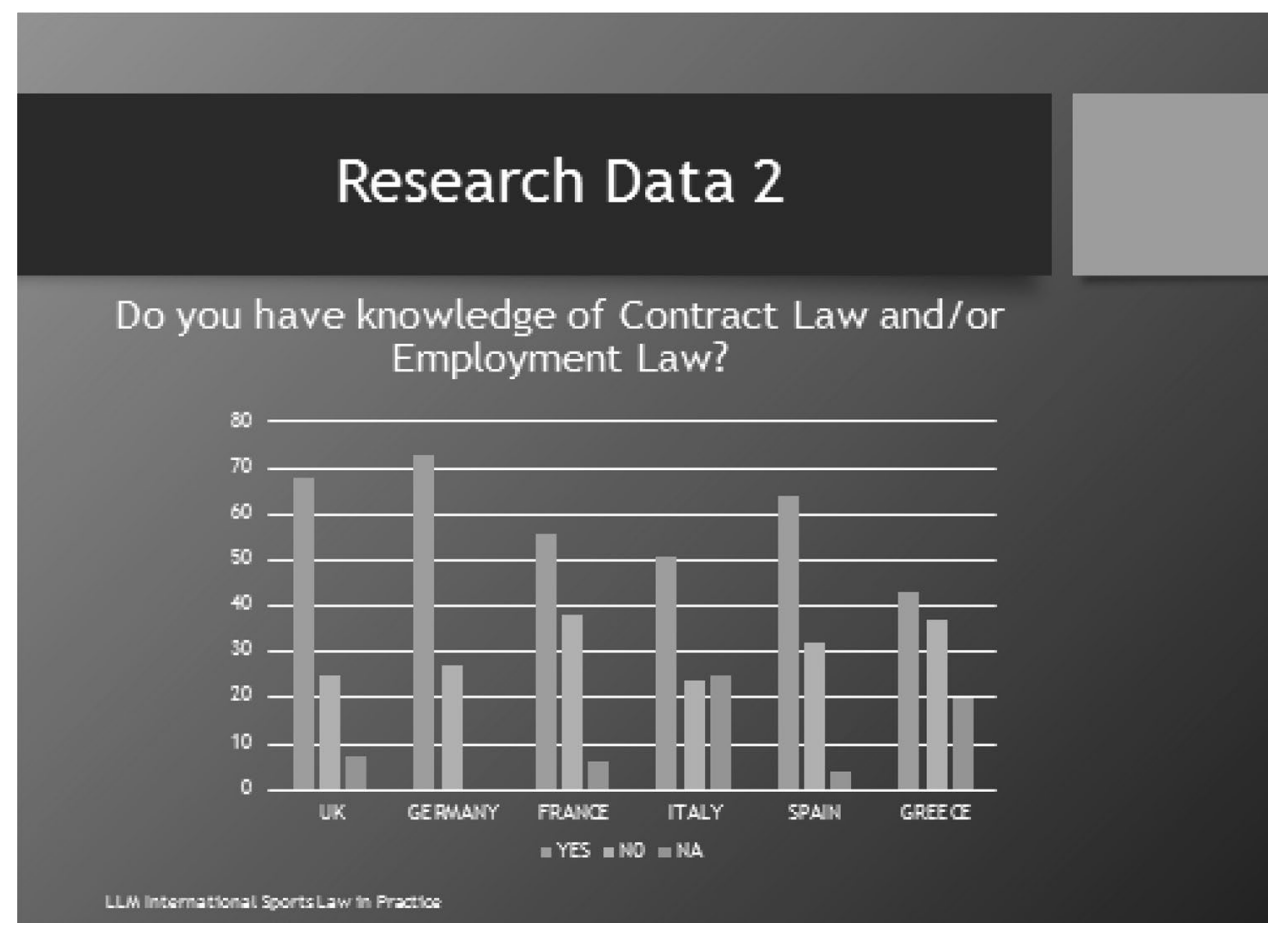

in the register of practising football agents and issue the necessary licence to practise.

The necessity of such stringent and strict qualification criteria must not be underestimated, nor must be dismissed at face value. The arguments outlined above, as well as our research and its empirical data in the next few lines, illustrate clearly the reasons for the creation of a comprehensive regulatory framework, based on a solid legal foundation. It is only when such strict qualification criteria are met, that public confidence in the governance of football agents can be restored. In the following lines, our readers will examine and evaluate our research findings that confirm the need for the introduction of our proposals.

As it was explained in the methodology section, our research was conducted over a period of 28 months in six European countries with questionnaires sent to registered football agents in their respective countries. The answers were anonymous, and they were collected and received by independent third parties. There was a remarkable response, where in all instances, $72.6 \%$ of the totality of agents returned their questionnaires. This confirms, to a very large extent, the validity of the data received and evaluated by us.

\subsection{Research data $1^{32}$}

In the first analytical set of data that we can reveal, the following important question was asked: 'Do you fully know/ understand the FIFA Regulations on Intermediaries?' The findings from the response received are somehow indicative of the current trend in this discipline and confirm that a large number of current football agents do not fully understand the current regulations. In some countries, our data suggest that almost 3 out of 10 agents lack such knowledge. Given the importance of the advice and the trust and confidence a player places on an agent, we conclude that the current system of deregulation causes a significant problem, as it may create serious ramifications not only for the professional people involved, but also for the sport as a whole. In essence, the lack of knowledge of the relevant regulations may lead some agents to produce an erroneous advice to their clients and create contractual problems of an irreversible nature. In one of our interviews, one of the respondent-agents admitted that they did not fully understand some of the regulations, but they did not wish to show such lack of knowledge and understanding to their clients. Similarly, they felt that seeking the advice of a legally qualified professional was a lengthy process and an expensive one. They also admitted that they were prepared to take the risk and advise their clients, as the profit out of the relevant transaction was too large to ignore and it was worth the risk. The conclusion here is self-evident and one that cannot be ignored by the regulators.

\footnotetext{
$\overline{32 \text { See Fig. } 2 .}$
} 
Fig. 4 Research Data 3

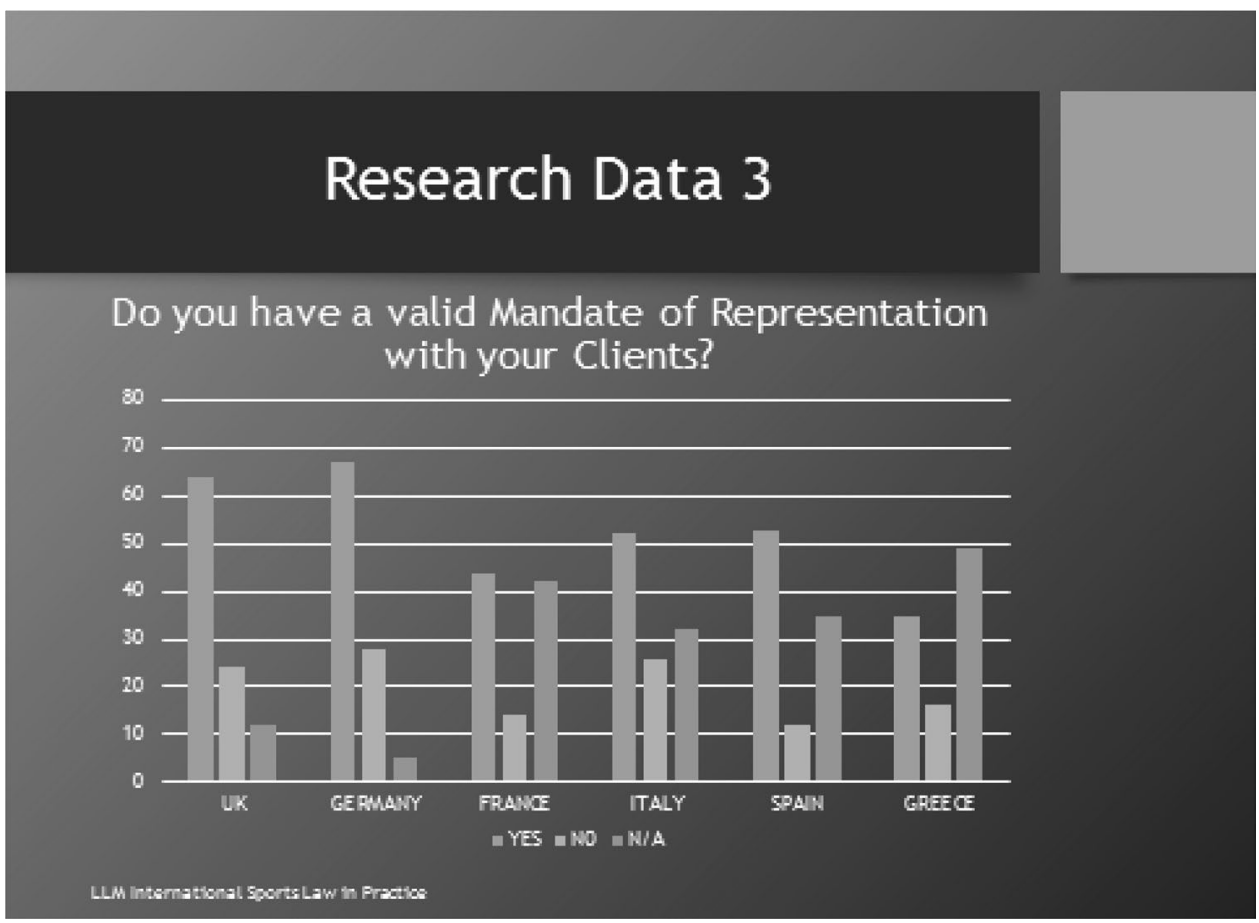

\subsection{Research data $2^{33}$}

In the second set of empirical data, the participants were asked the following question: 'Do you have knowledge of Contract Law and/or Employment Law?' Again, these particular data indicate a serious problem, as in some countries almost 4 out of 10 agents confirm that they have no knowledge of such legal disciplines. It is submitted that as the relationship between players and clubs is a contractual/ employment one and the advice given by agents to players has as a subject matter such contractual relationship, it is not far-fetched or illogical to suggest that lack of knowledge of these specific areas of law may also create serious ramifications for those involved. Both the interviews we conducted and the responses to our survey identified important data regarding pre-advice and post-advice issues that may arise. In this instance, $23 \%$ of the respondents stated that they would consult a qualified lawyer in case they feel they need assistance with issues of contract law/employment law, whereas another $11 \%$ of the respondents stated that they prefer to take the risk and advise their clients even though they had no knowledge of the relevant law. A smaller $5 \%$ of the respondents stated that they did not need such knowledge as they relied on the buying and selling clubs to confirm all issues.

\footnotetext{
33 See Fig. 3.

34 See Fig. 4.
}

\subsection{Research data $3^{34}$}

In the third set of empirical data, a very important question was asked: 'Do you have a valid Mandate of Representation with your Clients?' The data gathered from the responses to this question are most alarming and forms, perhaps, one of the most worrying aspects regarding the practice of football agency. The data confirm that a large number of agents currently operate without a valid contract (mandate) of representation with their clients. This creates not only a legal problem, but also an ethical one, which exposes not only the ineffectiveness of self-regulation, but primarily, it exposes the players who deal and negotiate with such football agents. ${ }^{35}$ From these particular data, our readers may elicit that, in some countries, almost half of the practising agents operate without a valid contract of representation with their clients. Given that FIFA places enormous reliance on contractual stability and wishes to maintain such contractual stability at all times, it is important to suggest that such outcome exposes one of the routes to the problem and undermines not only contractual stability, but also FIFA's authority (and subsequently the one of national federations) to properly regulate football agents and assert its authority on them. ${ }^{36}$ In some countries, a staggering $40 \%$

\footnotetext{
${ }^{35}$ From experience, it is sometimes the case that several players do not wish to be tied up to a contract with an agent.

36 This is also true, particularly at national level where an increasing number of cases before national courts can be identified. See, for example, the UK experience - Breach of contract and/or inducement
} 
Fig. 5 Research Data 4

\section{Research Data 4}

\section{Do you follow the recommended 3\% fee benchmark suggested by FIFA?}

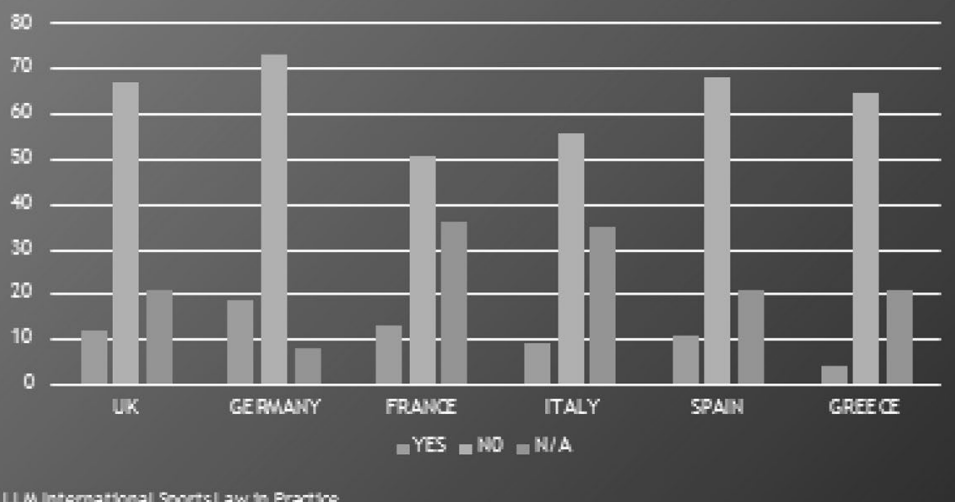

LLM intematkenal SoertsL Lw th Freatios

Fig. 6 Research Data 5

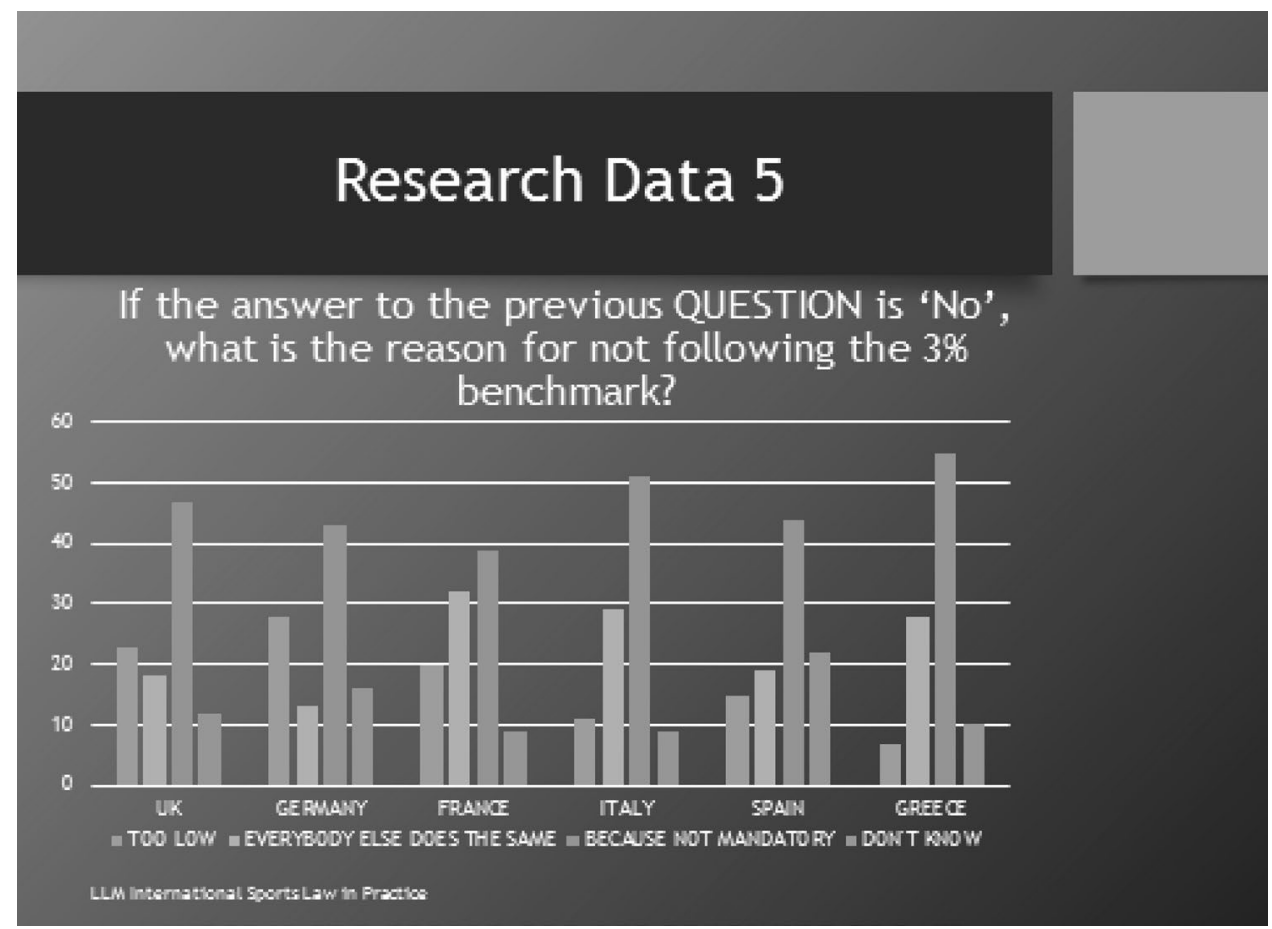

$\overline{\text { Footnote } 36}$ (continued)

to breach: Anthony McGill v. The Sports and Entertainment Media Group ('SEM') [2016] EWCA Civ 1063; [2017] 1 WLR 989; Breach of fiduciary duty: Imageview Management Ltd v Jack [2009] EWCA Civ 63; [2009] 2 All E.R. 666. of the respondents admitted that they do not hold a valid mandate of representation with their clients (despite FIFA's clear instructions on the point). An alarming 18\% stated that they do not do so, because there are no repercussions, whereas another $13 \%$ stated that their clients do not want such contractual obligation (mandate), and if the agents were to pressurise the players into signing one, they may lose such 
Fig. 7 Sanctions a

\section{The Future - Sanctions}

Disciplinary proceedings against intermediaries

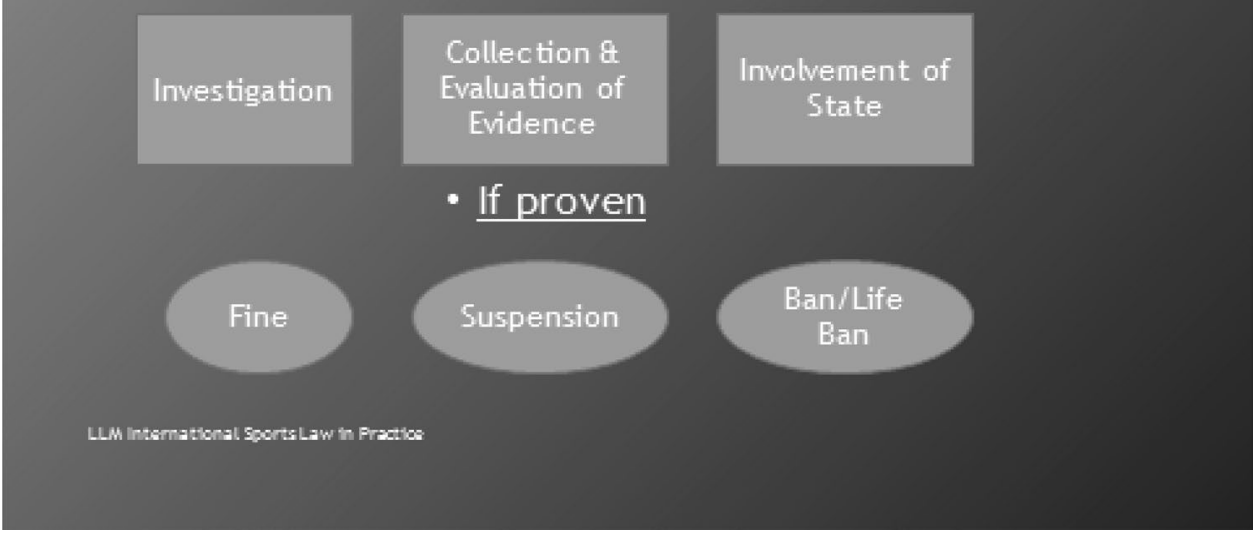

players from their representation. In one of the interviews we conducted with a Premier League manager, such manager acknowledged that they have dealt with unauthorised agents, simply because the player was to good to lose out on. On the question, of whether they (manager) understood the risk of clubs dealing with unauthorised agents, they explained that the club knew the risk, but still went on to authorise (the club) the transaction.

\subsection{Research data $4^{37}$}

In the fourth set of empirical data, the following question was posed to the participants: 'Do you follow the recommended 3\% benchmark fee suggested by FIFA?' You may elicit from the responses that no further elaboration is required. Almost over 7 out of 10 football agents do not follow such recommendation by FIFA. This could easily allow one to conclude, with respect, that FIFA's recommendation here is much ado about nothing and it is equally evident that such recommendation is unworkable. The following data, however, reveal further evidence.

\subsection{Research data $5^{38}$}

In the fifth set of empirical data, we posed the following question to the participants: 'If the answer to the previous

\footnotetext{
37 See Fig. 5.

38 See Fig. 6.
}

QUESTION is 'No,' what is the reason for not following the 3\% benchmark?' The data gathered from the responses are truly revealing of the mentality currently in place and justifies the argument that such suggested benchmark is unworkable. A closer examination, however, indicates that over 5 out of 10 agents do not follow such recommended benchmark because 'it is not mandatory.' This may generate the logical enquiry as to what the result would be, if such benchmark were to become mandatory. This remains to be seen, but in the author's opinion (as it is explained above), even in the hypothetical scenario where the $3 \%$ benchmark applies, its compulsory operation would be short-lived for two important reasons: firstly, it may fall foul of current European competition law policy and secondly, the application of such benchmark would create an arbitrary environment and one which would be evidently disproportionate and unequal between different players' transfers (where agents' fees are concerned).

\section{Proposals continued: solutions}

\subsection{The future: financial transparency}

Current public opinion resigns to the view that there is an enormous amount of money in the business of football and certain transactions involving football agents and subsequent payments to them are illegal and unethical. With this in mind, we propose a rather radical approach in dealing with payments to agents. It is submitted that financial 
Fig. 8 Sanctions b

\section{The Future - Sanctions}

- Disciplinary proceedings against clubs

If proven (clubs dealing with suspended/banned/unlicensed intermediaries)

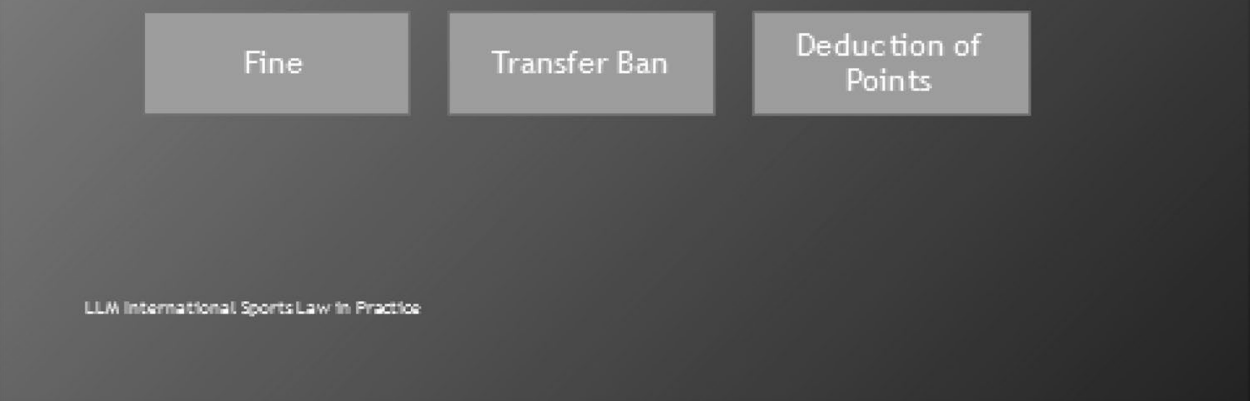

transparency, particularly in the current situation before FIFA, is regarded as one of the cornerstones of the so-called change in the governance of football agents. Much of the objection towards the incredibly high and inflated fees of football transfers is directed against the secrecy of payments towards agents. There are certain ways by which such payments may be hidden and, consequently, football authorities, as well as tax authorities, cannot determine with certainty the financial transparency required from all stakeholders. With the present work, we propose the creation of a mechanism at national level, where all football clubs would deposit with their national federation, in advance, an estimate of the fees for licensed agents. This would mean that payments would become valid only via the national federation and only with the natural entity that can be identified in the transaction. If the entity in the transaction is a commercial entity (something which the author opposes), there should be a requirement of a registered football agent acting for the commercial entity and a clear identification of their role in the said transaction (whether they are paid agents or non-paid agents). In summary, we propose the following on the issue of financial transparency:

- Payments to agents via the National Federation.

- Clubs to deposit in advance intermediaries' fees with the National Federation.

- Restrictions on commercial entities with registration in 'tax havens.'

- Identification of intermediaries with a valid registration (and their role in the transaction) if acting via a commercial entity.
- Automatic tax deduction (agents' fees) in the country of the purchasing club.

\subsection{The future: sanctions against agents ${ }^{39}$}

One of the important aspects of the current analysis relates to the lack of execution of the appropriate sanctions currently in place. This proposal is one of the most fundamentals of the current work, as it identifies, and promotes, the state as an important player in the investigative stage of disciplinary proceedings against agents. One of the main problems with the current regulations concerns the inadequate or non-existent application of sanctions against unscrupulous agents. Lack of execution and application of rules creates a stigma and an anathema of the worst kind. One may argue that such proposal may lead towards a form of criminalisation, but equally an argument may be submitted that the current nature of disciplinary law may lead us to conclude that there is an inevitable overlapping between the two, mainly because of the paternalistic basis that both kinds of regulation have. In the author's opinion, the fundamental basis of the problem is not the existence of strict rules, but, rather, the lack of effective and purposeful application of such rules.

In the premises, the current proposal suggests that external regulation is necessary, particularly at the investigative stage of the disciplinary process, where the state may assist in the collection and evaluation of evidence against the perpetrators. This is a necessary development, which must be

\footnotetext{
${ }^{39}$ See Fig. 7.
} 
Fig. 9 Sanctions c

\section{The Future - Sanctions}

- Disciplinary proceedings against national federations

If proven (federations failing to investigate complaints/apply sanctions)

Financial penalties, including withdrawal of funding
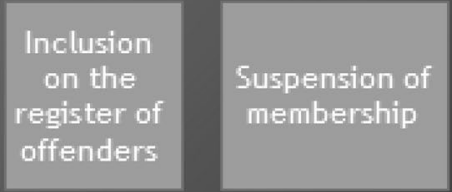

LuM intematkenal sportsLaw th Frectios

Fig. 10 Solution

\section{SOLUTION?}

- INDEPENDENT MONITORING COMMITTEES AT

NATIONAL LEVEL (SELF REGULATION \&

EXTERNAL REGULATION)

- FIFA TO ACT AS AN APPELATE BODY

APPLICATION, ENFORCEMENT AND EXECUTION

LLM Intematkonal SportsLaw in Fratks

inserted in the future set of regulations, as it would allow FIFA and the national federations to create a more sophisticated and comprehensive disciplinary framework and one which would observe transparency, consistency, certainty and equality.

\subsection{The future: sanctions against clubs ${ }^{40}$}

Provided that there is a close cooperation between selfregulation and external regulation (at the investigative

\footnotetext{
$\overline{40}$ See Fig. 8.
} 
stage of the disciplinary process), where the evidence may be collected and evaluated with the assistance of the State, it is submitted that when such evidence indicates malpractice on behalf of football clubs, sanctions must be applied, indiscriminately, against such clubs. Although one cannot argue that this is the rule (as opposed to the exception), nevertheless, there is an increasing number of football clubs, around Europe, who are prepared to complete transactions with unlicensed and/or unscrupulous agents. This suggests that certain clubs are complicit in activities that go beyond the sphere of legality and, in essence, create an environment of regulatory breaches. It is not enough, however, to identify such breaches and simply state that clubs are responsible. Where the evidence meets the standard of proof, sanctions must be imposed against such clubs, ranging from a simple fine, to a transfer ban and deduction of points. Having produced several arguments on the point, we conclude that such sanctions may not run contrary to the principle of proportionality.

\subsection{The future: sanctions against federations ${ }^{41}$}

Similarly, an argument needs to be made on the importance of the role of national federations in the investigation and prosecution of offences. In the premises, it is submitted that when national federations fail to adequately prosecute offences and/or apply 'home town' decisions, the regulatory system becomes ineffective and witnesses another step on the ladder of illegality. At this juncture, we may also witness an exasperation of the situation as the aggrieved party may remain without a remedy in terms of continuation of the disciplinary process. This is particularly relevant in light of the current regulations, as FIFA explicitly diverts application of regulatory responsibility, as well as judicial decision making, to national federations. The lack of remedies becomes even more serious a situation, given the lack of an appellate stage outside the national parameters (save where FIFA decides to intervene with its own decision making). This jurisdictional limitation, in conjunction with lack of sanctions at national level, makes the current regulations extremely ineffective and potentially irrelevant.

\subsection{The future: solution ${ }^{42}$}

In conclusion, it is proposed that an effective and workable solution to the problem would require a close cooperation between national federations and state authorities, particularly at the investigative stage, where evidence needs to be collected and evaluated. As suggested above, it is proposed

\footnotetext{
41 See Fig. 9.

42 See Fig. 10.
}

that an Independent Monitoring Committee must be created at national level, comprising of experts (unconnected to the national federation) from self-regulation and external regulation. Such committee will be responsible for the investigation, adjudication and application of the regulatory framework.

In line with the legal developments emanating from the European Court, FIFA must also work closely with state authorities, to ensure its regulatory framework is supported in areas that require a public response and assistance. It is true that in certain circumstances a private regulatory body such as FIFA must comply with national legislation (and where European countries are concerned, with EU law), particularly where employment and agency laws are concerned. As stated above, a number of countries are now commencing the creation of sport specific legislation for the activities of football agents, by taking into consideration corresponding provisions from employment law and agency law (as they are incorporated into their national Statutes). Countries without such national legislation are encouraged to follow such example, to ensure that there is harmonisation, worldwide, in the activities of football agents. This point was also addressed in the Piau case (as stated above) where it was acknowledged by the European Court that lack of specific national regulation/legislation, may create a necessity of qualitative restrictions in FIFA's regulatory framework of football agents.

Similarly, an argument can be made that FIFA has a unique opportunity to re-gain effective regulatory control over the activities of football agents, with the required degree of legality and order. Although there are several competent and able football agents, there are also, regrettably, several unskilled and untrained agents, who enter the market with the sole intention of making a quick profit. The European Commission may feel that entry restrictions to individuals have the potential of violating EU competition law; however, the European Commission has also acknowledged in the Piau case (as stated above) that it is important for a regulator to have some control over those who operate in this market, particularly when there is absence of national legislation and/or regulation. This is an important point which offers probity to our proposal for a closer cooperation between external regulation and self-regulation, regarding the activities of football agents.

Finally, FIFA must create a compulsory appellate level, where all disputes, on appeal from a national federation, are dealt with efficiently. A further appellate level to CAS must continue to exist also. This is an important procedural requirement which imposes necessary issues of safeguarding against abuse of power at national level and instances of miscarriages of justice. Such procedural requirement will also add further certainty and consistency in the advice offered to the different stakeholders in the regulation of football agents. 
It would also strengthen FIFA's legal framework and it will eliminate 'home town' decisions at national level.

\section{Conclusion}

It has been suggested, in this work, that there is an increasing need for cooperation between self-regulation and external regulation. Such is the importance of football for society that all consequences flowing from inadequate and ineffective regulation have the potential of damaging the image of sport and, therefore, instruct for a public, rather than a private response. To this effect, it is also important to conclude that those governing the regulation of agents must arrive at a specific path and decide to follow it without diversions. When one of my students recently asked me where selfregulation is going with this area of football law, I could not find a better answer than the one identified in one of Christopher Columbus' writings (written on his attempts to discover America): 'When I was travelling to America, I didn't know where I was going; when I arrived in America I didn't know where I were; when I left America, I didn't know where I had been.'

It follows that the only solution to this increasing anathema for self-regulation is a clear direction. The author is of the view that unscrupulous agents have no place in the sport of football and they must be eliminated. The current regulatory framework must be applied in a prudent and purposeful manner and all stakeholders involved must condemn unethical, immoral and illegal behaviour from such individuals ${ }^{43}$. More importantly, the different regulators in football must ensure they deal with complaints effectively and efficiently by applying the appropriate sanctions against such individuals. As prevention is always better than cure, it is submitted that agents must be qualified (based on the proposals in this work) and their regulation must, to a certain extent, be left to independent monitoring committees or the relevant state authorities (where collection and evaluation of evidence are concerned). It is only when tough and fair sanctions could apply against such individuals, that the problem of unscrupulous agents may be eliminated for ever.

December 2018

Open Access This article is distributed under the terms of the Creative Commons Attribution 4.0 International License (http://creativeco mmons.org/licenses/by/4.0/), which permits unrestricted use, distribution, and reproduction in any medium, provided you give appropriate credit to the original author(s) and the source, provide a link to the Creative Commons license, and indicate if changes were made.

\section{References}

Cetina K (1999) Epistemic cultures: how the sciences make knowledge. Harvard University Press, Cambridge

Deloitte (2018) Annual review of football finance

Kelso P (2009) Premier league wages soar as agents paid £66 million. Daily Telegraph, June 4

Latour B, Woolgar S (1986) Laboratory life: the construction of scientific facts. Princeton University Press, New Jersey

Magee J (2002) Shifting balances of power in the new football economy. In: Sugden J, Tomlinson A (eds) Power games: theory and method for the critical sociology of sport. Routledge, London, pp 216-239

Players' Agent Regulations (2006) FIFA

Players' Agent Regulations (2008) FIFA

Poli R (2010) Agents and intermediaries. In: Hamil Sean, Chadwick Simon (eds) Managing football. Elsevier, Oxford, pp 201-216

Regulations on Working with Intermediaries (2015) FIFA

Publisher's Note Springer Nature remains neutral with regard to jurisdictional claims in published maps and institutional affiliations.

43 Ioannidis G (2018) The fiduciary duty of football intermediaries and the conflict it creates. https://www.linkedin.com/pulse/fiduciaryduty-football-intermediaries-conflict-gregory-ioannidis/ 